\title{
Um estudo sobre a Sociologia da Música, de Theodor W. Adorno e sua atualização na cultura-mundo hipermoderna
}

\author{
Claudia Castro de Andrade*
}

\begin{abstract}
Resumo: A obra "Sociologia da Música" descreve o aspecto musical como algo intrínseco ao sociológico e, considerando-se a música como um fenômeno social, torna-se evidente e necessária investigação do curso de seu desenvolvimento. Mais que a música propriamente dita, Theodor Adorno se dedica a uma teoria do ouvinte, à recepção musical e aos elementos psicológicos envolvidos. Segundo Adorno, a recepção da música por parte do ouvinte revela modos passivos de comportamento, mas a regressão da audição representa a regressão de pessoas conscientemente neutralizadas que não conseguem pensar de um modo que não seja coletivamente partilhado, cujas convenções estéticas inibem a formação de uma consciência autônoma. Tenciona-se, portanto, relacionar o pensamento de Adorno com os valores da hipermodernidade e da cultura-mundo, de Lipovetsky, fundamentadas na moral do consumo, da individuação, desumanização e reificação da consciência, cuja dialética entre o universal e o particular tende à igualitarização dos modos de vida e conduta.
\end{abstract}

Palavras-Chave: Estética; Sociologia da música; Hipermodernidade.

\section{A study on The Sociology of Music, by Theodor W. Adorno, and its update on the hypermodern world-culture.}

\begin{abstract}
The book "Sociology of Music" describes the musical aspect as intrinsic to the sociological and, considering music as a social phenomenon, it becomes evident and necessary investigation of the course of its development. More than music itself, Theodor Adorno is devoted to a listener theory, musical reception, and the psychological elements involved. According to Adorno, the listener's reception of music reveals passive modes of behavior, but the regression of hearing represents the regression of consciously neutralized people who cannot think in a way that is not collectively shared, whose aesthetic conventions inhibit the formation of a person. autonomous consciousness. It is intended, therefore, to relate Adorno's thought with Lipovetsky's values of hypermodernity and world-culture, based on the moral of consumption, individuation, dehumanization and reification of consciousness, whose dialectic between the universal and the particular tends to equalization of ways of life and conduct.
\end{abstract}

Keywords: Aesthetics; Sociology of music; Hypermodernity.

\section{O espírito prático e objetivo e a padronização coletiva}

A relação do pensamento adorniano com alguns conceitos trazidos pelo filósofo Gilles Lipovetsky se da no sentido de considerar o aspecto sociológico da música com um tempo marcado pela hipermodernidade e seus valores. Adorno chamou atenção para a mudança do comportamento social em face das transformações e condições sociais. Da mesma forma, Gilles Lipovetsky também busca destacar a modificações de padrões estéticos estimulados pelos valores do que ele chama "hipermodernidade".

\footnotetext{
* Mestre em História das Ciências e das Técnicas e Epistemologia, pela Universidade Federal do Rio de Janeiro (UFRJ). Doutoranda em Filosofia, pela Universidade do Estado do Rio de Janeiro (UERJ). E-mail: claudiacastrodeandrade@gmail.com.
} 
De acordo com Lipovetsky, o predomínio do presente instaurado numa modernidade que negocia com passado se transforma em um novo tempo de integração mediante a lógica do mercado, do espírito pratico e objetivo e da padronização coletiva dos gostos e costumes. Assim, “desde os anos 1940, Adorno e Horkheimer insurgiam-se contra a fusão 'monstruosa' da cultura, da publicidade e do divertimento industrializado que acarreta a manipulação e a estandardização das consciências” (Lipovetsky, 1989, p. $15)$.

A estandardização da consciência significa a padronização coletiva do gosto mediante as imposições do mercado e, como afirma Adorno, se assemelha à "manipulação fascista, que revestia a imposição coletiva dos atomizados com as insígnias da comunidade popular précapitalista e originalmente natural" (Adorno, 2011, p. 72). Assim, a relação entre a identidade individual e a dimensão coletiva

somente faz sentido como algo que estabelece uma mediação com o mundo a partir de uma dinâmica histórica que sedimenta em suas formas um modo coletivamente instituído de preservar a imagem da sociedade e dos indivíduos (FREITAS, 2001, p. 38).

Até mesmo como forma de proteção, o homem mimetiza o comportamento social no sentido de salvaguardar-se e a ausência de reflexão do objeto e de si o faz perder a capacidade de diferenciar (Adorno; Horkheimer, 1985). A sobrevivência demanda a assimilação dos costumes, tabus e das práticas disciplinares. Como lembra Adorno, a civilização precisou superar a natureza enrijecendo-se contra ela mediante o controle das manifestações humanas estimulando o comportamento mimético ocasionando, assim, a vitória da sociedade sobre a natureza. (Adorno; Horkheimer, 1985).

Segundo Adorno, "a imitação se põe a serviço da dominação na medida em que até o homem se transforma em um antropomorfismo para o homem" (Adorno; Horkheimer, 1985, p. 169). Nesses termos, tendo se adequado às mudanças históricas e, sendo mediada pelo espírito prático e objetivo da época, a linguagem musical, cuja manifestação espiritual coletiva se instaura, se expande de modo ilimitado e padronizado sob o qual o caráter de mercadoria se sobrepôs insuportavelmente (Adorno, 1986, p. 151), reconstituindo-se e legitimando-se como cultura mediante a expectativa de aderência ao grupo.

A crescente complexidade técnica favorecida pelos meios de produção mecânicos e de massa que causou o aumento do número de ouvintes não impediu, entretanto, a redução de ouvintes competentes. Como lembra Adorno, o bom ouvinte, em face do processo de aburguesamento da sociedade, está cada vez mais raro. Mas, o processo de empobrecimento da recepção musical não caracteriza, entretanto, a antinomia entre os progressos econômicos e tecnológicos e a cultura, se entendermos 
cultura nos termos de uma "cultura-mundo" hipermoderna que cria um pseudoindividualismo na medida em que se direciona, de fato, para a massa. Essa cultura de massa que atua sob a ótica de um prazer imediato e recreativo e que "não trabalha senão para produzir uma pseudoindividualidade, torna 'fictícia uma parte da vida de seus consumidores"” (Lipovetsky, 1989, p. 222.).

Pela análise da cultura de massa apreendida como máquina destruidora da razão, empresa totalitária de erradicação da autonomia do pensamento, a intelligentsia formou um bloco comum, estigmatizando numa mesma voz a ditadura degradante do consumível, a infâmia das indústrias culturais (LIPOVETSKY, 1989, p. 15).

Ao falar de moda, Lipovetsky não a significa como mera descrição do que as mídias impõem diariamente como objetos industrializados. A moda independe de conteúdos e se refere à nossa qualidade e necessidade mimética. Contudo, a moda hipermoderna se rende ao império do efêmero, o qual é o império da novidade, do imediatismo já que a "a imitação dos antepassados apagou-se diante da dos modernos, o espírito costumeiro cedeu o passo ao espírito de novidade” (Lipovetsky, 1989, p. 268).

Assim como a "indústria cultural" dos frankfurtianos não é algo físico, a moda nos termos descritos por Lipovetsky não é algo apenas associado aos objetos físicos e materiais que consumimos, mas também ligado à formação e direcionamento de uma consciência na qual é ressignificado o próprio termo de arte e cultura. A moda ajuda a construir a manifestação estética e coletiva do juízo de gosto e tudo aquilo que é endossado pela sociedade, pois é o que define todos os segmentos culturais, nossas práticas, pensamentos e comportamentos transformando a própria cultura, na medida em que se territorializa por meio de ações coletivas consentidas.

É preciso insistir nisso: na genealogia da moda, são os valores, os sistemas de significação, os gostos, as normas de vida que foram 'determinantes em última análise', são as 'superestruturas' que explicam o porquê dessa irrupção única na aventura humana que é a febre das novidades. Substituindo a referência do passado pela do presente, a moda instituiu uma ruptura radical na ordem do tempo legítimo (LIPOVETSKY, 1989, p. 61-62).

A cultura, de modo geral, tornou-se, então, refém da imediaticidade hipermoderna e, a imprecisa, contingente, efêmera e instantânea edificação do futuro, que constitui a perda de referência do passado, decorre de um imediatismo histórico. E 
sociais, sem vontade política, mas numa era reciclada pela forma moda a história é mais do que nunca aberta, o modernismo conquistou tal legitimidade social que a dinâmica do reerguimento de nossas nações é mais provável que seu lento desaparecimento (LIPOVETSKY, 1989, p. 14).

O objetivo aqui, desse modo, não é produzir a contradição e, por conseguinte, tampouco resolver qualquer impasse entre pensadores de diferentes contextos, mas, ao contrário, mostrar a atualização do pensamento de Adorno com o de Lipovetsky, na medida em que as diferenças e dicotomias do período moderno e estruturalista ainda prevalecem, pois não foram, de fato, superadas, mas negociadas.

O pensamento de Adorno, desse modo, é aqui atualizado e complementado pelos valores da "hipermodernidade", os quais revelam o imediatismo, o consumo e a moda, bem como o coroamento social do presente que reduz ou desdenha dos modelos do passado, ao mesmo tempo em que, contraditória e anacronicamente, se aproveita dele. Como afirma Lipovetsky, "para a cultura industrial, o presente histórico é medida de todas as coisas, ela não temerá a adaptação livre, o anacronismo, a transplantação do passado no presente, a reciclagem do antigo em termos modernos" (Lipovetsky, 1989, p. 210). Assim, portanto, mesclam-se valores tradicionais com necessidades mercantis.

\section{Os tipos de comportamento musical}

A estruturação sistemática dos tipos de comportamento musical corresponde às condições sociais em que se encontram. As transformações técnicas ocorridas, sobretudo, no século XX orientaram hábitos, necessidades e a consciência estética, isto é, nossos valores e afetos. A sensação primária e sem esforço reflexivo de que algo faz parte de nossa vida causa a vaga recordação que se naturaliza em nossos sentimentos fazendo-nos legitimar sua institucionalização e, a experiência, mediante a vaga recordação do objeto inculcado na consciência, orienta, assim, a efetiva identificação do mesmo produzindo a rotulação do objeto a fim de facilitar sua própria identificação.

Como diz Adorno, um determinado hit se transforma num hit tal. A rotulação parte, desse modo, de um acordo coletivo que oferece o prazer da apropriação do objeto compartilhado e socialmente endossado. Mediante a permanência do objeto na memória do ouvinte, dado seu consentimento passivo, o objeto passa a orientar suas expectativas, tomando forma imperativa em relação a um sujeito passivo frente ao processo de estímulo-resposta a que está exposto, o que o faz reconhecer e transferir, desse modo, o prazer sentido ao objeto.

Segundo Adorno, a transferência psicológica é o componente final do processo de reconhecimento e não se aplica a qualquer melodia, mas somente aquelas que de alguma agencia avaliza e autoriza seu reconhecimento definindo-a como "sucesso". O 
próprio conceito do que é ou não sucesso musical depende, além disso, da repetição nas rádios que condiciona o ouvinte ${ }^{1}$ (Adorno, 1986) estimulando-o a aceitar e definir o que é ou não é popular (Adorno, 1986). Assim, como lembra Adorno, a música cowboy se naturalizou no gosto popular em regiões em que vivem cowboys (Adorno, 2011).

O objeto, por meio de todo esse mecanismo psicológico envolvido, funciona como sedução atuando no sentido de orientar valores e moldar as massas, pois "os usuários da diversão musical são eles mesmos objetos" (Adorno, 1986, p. 137). A aceitação popular, portanto, deve ser devidamente estimulada através da contextualização dos meios de comunicação de massa. Apropriadamente para esse pensamento, Adorno usa o termo "neutralização da cultura", no qual afirma que "a antinomia social consiste precisamente na enorme distância entre a qualidade intelectual, de um lado, e as demandas dos consumidores, por sua vez já manipuladas, por outro" (Adorno, 2006, p. 92).

Uma das características que facilita essa antinomia é o aceite passivo aos moldes do consumo. A aversão ou desvalorização e escárnio ao que não pertence ao tempo presente, à moda e ao popular significa, na verdade, produzem a perda de referência ou, como chama Karl Jaspers, citado por Adorno, de “orientação existencial”.

\begin{abstract}
$\mathrm{Na}$ adolescência desenvolve-se, por exemplo, o tipo que afirma - se posso recorrer mais uma vez à música - : 'A época da música séria já passou; a música de nosso tempo é o jazz ou o beat'. Isto não é uma experiência primária, mas sim, se posso usar a expressão nietzschiana, um fenômeno de ressentimento. Essas pessoas odeiam o que é diferenciado, o que não é moldado, porque são excluídos do mesmo e porque, se o aceitassem, isto dificultaria sua 'orientação existencial', como diria Karl Jaspers (ADORNO, 2006, p. 149-150).
\end{abstract}

Em sua teoria do ouvinte não poderia faltar ênfase aos "tipos de ouvintes". Adorno define vários tipos de ouvintes e "a intenção da tipologia é, com consciência dos antagonismos sociais e de maneira plausível, agrupar a descontinuidade das reações diante da própria música" (Adorno, 2011, p. 58).

O ouvinte do entretenimento (Erschütterung), cuja característica, é a fraqueza do $\mathrm{Eu}$, é o tipo que "só se deixará descrever adequadamente quando contextualizado a partir dos meios de comunicação de massa como o rádio, o cinema e a televisão" (Adorno, 2011, p. 79). A sedução e a espetacularização estéticas da cultura-mundo, que tem como princípios a novidade e o consumo, encontram no entretenimento seu

\footnotetext{
${ }^{1}$ Adorno comenta que a geração do rádio constitui uma massa de indivíduos, principalmente jovens, do tipo ritmicamente obediente, cujo estímulo supera a individualidade e pressupõe imediatamente o desejo de obedecer.
} 
ambiente favorável e o tipo de ouvinte do entretenimento é o consumidor cultural que, sem perceber-se, é absorvido pela indústria cultural que racionalmente o instrumentaliza. Impedido pela massificação de formar uma consciência crítica, o ouvinte do entretenimento é indiferente ao que é falso e não compreende, portanto, a imperativa contradição entre consciência correta e mundo falso. Sobre esse enfraquecimento do eu, Freitas comenta:

[...] uma perda do referencial previamente estabelecido, como que uma invasão da esfera da subjetividade por um processo alheio, em que a consciência percebe-se como determinada intimamente através de algo que lhe retira o centro de sua própria fixidez identitária (FREITAS, 2005, p. 46).

Entre outros tipos de ouvintes, temos o expert que, segundo Adorno, se comparado com as condições sociais dominantes é aquele que se comportava de forma utópica e desumana e que sobreviveu até o século XIX nos círculos nobres e aristocráticos, mas que se tornou mais raro em face do "processo de aburguesamento" da sociedade (Adorno, 2011).

O consumidor cultural, um tipo burguês, cuja relação fetichista e idólatra com a música depende "da legitimação pública do que é consumido" (Adorno, 2011, p. 64), é o "homem da aclamação". É aquele tipo que se aparta da massa e reage de modo hostil e elitista, mas cujo conteúdo próprio poder-se-ia comparar ao dela. Esse tipo não está distante da massa e constitui uma falsa consciência, cuja padronização generalizada Lipovetsky (1989) chama de "pseudocultura espetacular". Esse tipo, portanto, é aquele que entende a arte como consumo daquilo que somente é legitimado, aceito e definido coletivamente pela massa e, desse modo, "para ele, a música não consiste numa estrutura de sentido, mas numa fonte de estímulo" (Adorno, 2011, p. 76).

Outro tipo que merece atenção, definido por Adorno como "ritmicamente obediente', é o ouvinte emocional. Segundo Adorno, a pressão civilizatória, sobretudo nos países anglo-saxões, cria uma rigidez social que nos torna, ao contrário, frágeis e emotivamente reféns da necessidade de emoção. A produção da emoção auditiva ou, nas palavras de Adorno, a estandardização da melancolia, que transforma a música na mãe que consola o filho choroso, representa a catarse para as massas.

\section{A modernidade e sua atualização hipermoderna}

As transformações que surgiram durante o período da primeira metade do século XX suscitaram discussões sobre as novas técnicas de composição, as quais romperam, 
de certo modo, com moldes tradicionais, fundadas sob os conceitos de liberdade e emancipação que, entretanto, não se apercebe num mundo administrado pela lógica da técnica, do consumo e do mercado. Disse Adorno: "o modernismo asfixia a modernidade" (Adorno, 2011, p. 174).

Adorno admite que as normas estilísticas de outrora imprimiam e mascaravam o que era balbuciado como música. A "mais pobre peça moderna é, ao menos, superior a essa normalidade, na medida em que desdenha tal aparência” (Adorno, 2011, p. 337). Embora não seja uma mentalidade exclusivamente moderna, a consciência musical da modernidade configura o momento, cuja "relação espontânea com o objeto, baseia-se na capacidade de ter experiências" (Adorno, 2011, p. 337), mediante a identificação e intimidade com o objeto, orientadas, vale lembrar, "por indícios de um pensar reificado, cujo órgão responsável pela apreensão do específico acha-se atrofiado" (Adorno, 2011, p. 336).

Contudo, Adorno afirma que "existe modernidade moderada desde que a modernidade existe" (Adorno, 2011, p. 355). Assim, se de um lado, somente os provincianos mantinham a defesa de um tradicionalismo composicional, do outro, porém, a nova música ainda não tinha muitos adeptos. Era preciso, então, equilibrar as produções modernas com a técnica dodecafônica, cujo método ia contra a irracionalidade de não se fazer uso da necessidade técnica.

\footnotetext{
(...) tal como o definia Schõnberg; do mesmo modo, tudo o que se deixa agrupar sob a égide desse slogan não representa nenhum gênero especial de música, mas um procedimento técnico que racionaliza, por assim dizer, aquilo que adquiriu forma na dinâmica da linguagem musical; em uma escuta ao vivo, torna-se muito difícil ao leigo diferenciar as composições livremente atonais das dodecafônicas, tais como, por exemplo, as do Webern do período intermediário. // Apesar disso, o termo música dodecafônica tornou-se corrente para descrever de maneira indiferenciada tudo o que não é tonal, qual uma fórmula para o acolhimento daquilo que não é acolhido. (ADORNO, 2011, p. 266).
}

Segundo Adorno, "no comportamento do sujeito composicional da música mais recente, acha-se refletida a abdicação do sujeito" (Adorno, 2011, p. 338). Sendo, a necessidade e a formação do gosto, universais, edificam-se, assim, as características previsíveis da coletividade. Tal universalidade preconcebida, opaca e complacente, como nas próprias palavras de Adorno, produz o particular. Mediante uma regra autoimpositiva do universal, tal como também define Adorno, "o particular converte-se em acaso abstrato e livre de toda determinação própria” (Adorno, 2011, p. 340). Por meio 
da perda da autonomia se produz um automatismo na construção da própria subjetividade, cujo estímulo de energia coletiva cria a devida ambiência para a produção de afetos partilhados.

Outra característica que vale ser ressaltada é a heterogeneidade. A heterogeneidade da modernidade composicional revela que "dentre os compositores mais marcantes, é possível encontrar filhos de industriais e patrícios ao lado de artistas que vivem nas mais módicas situações" (Adorno, 2011, p. 346). Tais diferenças de procedência não impedem, entretanto, suas relações e permanentes trocas de experiências. Tendo o cultivo da individualidade se tornado antiquado, essa heterogeneidade social se relaciona, vale lembrar, com a perda da identidade e abdicação do sujeito e, ao mesmo tempo, é movida pelo sentimento de coletividade que recusa o isolamento e tudo o que não esteja em acordo com o conteúdo humano efetivamente compartilhado, como a moda e a crise. A arte necessita do endosso e da publicidade e deve, necessariamente, estar ligada aos afetos e sentimentos do grupo social. Como lembra Adorno, "as consequiências da crise social do indivíduo estendemse, inclusive, à gênese das obras" (Adorno, 2011, p. 341) e "a musica é essencialmente igual à sociedade na qual é exorcizada e da qual prepara uma cópia desbotada" (Adorno, 2011, p. 350), como modo de identificação da arte com o mundo da vida e da experiência. Nesse sentido, a gênese da consciência reificada se encontra nas relações repressivas da sociedade que moldam e administram o ethos hipermoderno.

A modernidade descrita por Adorno era integradora de nichos polarizados, contrários. Segundo Adorno, "a divisão do mundo em alguns poucos blocos de poder se dá a conhecer musicalmente nas mais grosseiras diferenças entre estilos" (2011, p. 328329). A música sofre as influências das tendências sociais que a politizam.

\footnotetext{
A profundidade das relações entre música e sociedade poderia expressar, antes, o fato de que as obras (...) 'representam' tendências sociais tais como a cisão do mundo em grandes sistemas supranacionais. Assim, o neoclassicismo (...) perdeu sua força de atração, seja por causa de sua estéril produção, seja em virtude da crítica teórica, enredando-se, outrossim, de maneira demasiadamente explícita em ideologias reacionárias para que, após a queda do fascismo, os jovens intelectuais dentre os compositores tivessem, de bom grado, comprometido-se com ele (ADORNO, 2011, p. 329).
}

Se a modernidade, tratada por Adorno, ainda destacava o binarismo presente na divisão do mundo, o qual compreendia espírito de tradição, hierarquia de gêneros em seus respectivos e demarcados papéis sociais, fé na ciência e no progresso ilimitado, 
maniqueísmo político, ideologias totalitárias e a polaridade econômica resultante desses conflitos, o novo tempo se unifica e se globaliza por meio de suas características próprias. As diferenças não desaparecem, são negociadas.

\begin{abstract}
Eleva-se uma segunda modernidade, desregulamentadora e globalizada, sem contrários, absolutamente moderna, alicerçando-se essencialmente em três axiomas constitutivos da própria modernidade anterior: o mercado, a eficiência técnica, o indivíduo. Tínhamos uma modernidade limitada; agora, é chegado o tempo da modernidade consumada (LIPOVETSKY, 2004, p. 54).
\end{abstract}

De um tempo demarcado por grupos distintos, hierárquicos e polarizados, cujo espírito de tradição ainda os mantinha, de certo modo, coesos, integrados, o novo tempo destaca o fracasso das ideologias e a evidente diversidade social; a expectativa no futuro cede lugar ao imediatismo do presente e as utopias perdem o sentido. Como diz Lipovetsky, "era evidente uma modernidade de novo gênero a que tomava corpo, e não uma simples superação daquela anterior" (2004 p. 52). As transformações sociais, políticas e estéticas configuraram a modernização da própria modernidade, cuja cisão fez surgir uma nova sociedade moderna. Esse novo tempo com moldura plural, multiculturalista, do qual emergem questões identitárias como práticas, não epistemológicas, mas enunciativas - na descrição de Homi Bhabba, - exigia uma definição própria.

O epistemológico está preso dentro do círculo hermenêutico, na descrição de elementos culturais em sua tendência a uma totalidade. $\mathrm{O}$ enunciativo é um processo mais dialógico que tenta rastrear deslocamentos e realinhamentos que são resultado de antagonismos e articulações culturais - subvertendo a razão do momento hegemônico e recolocando lugares híbridos, alternativos, de negociação cultural (BHABHA, 1998, p. 248).

Nesse novo contexto, chamado de pós, e marcado pelo descontentamento político, se questionou tradições, autoritarismo e disciplinas. Um novo momento chegou, mas não tardou em ser superado. Como afirma Lipovetsky, "tudo foi muito rápido: a coruja de Minerva anunciava o nascimento do pós-moderno no momento mesmo em que se esboçava a hipermodernização do mundo" (2004, p. 53). Assim, a modernidade foi atualizada e com ela, os valores de outrora. Os movimentos de grupos em suas respectivas causas caminham lado a lado com o crescente individualismo e tais grupos se ajustam sob o reconhecimento e aceite da divisão de espaço entre todas as causas por mais contraditórias que sejam. Desprendidas de ideologias rígidas, as contradições convivem, se toleram, quiçá, na tentativa de tornar a democracia, aparentemente, uma práxis. Tudo se torna moda, válido e legitimamente 
estimulado sem qualquer dicotomia. Múltiplos e distintos discursos compartilham espaços de legitimidade. Contudo, como lembra Bhabba, os termos pós ou hiper, não representam um simples processo de redefinição, ou uma mera seqüencialidade ou extravagância terminológica:

Se o jargão de nossos tempos - pós-modernidade, pós-colonialidade, pósfeminismo - tem algum significado, este não esta no uso popular do "pós" para indicar seqüencialidade (...) Esses termos que apontam insistentemente para o além só poderão incorporar a energia inquieta e revisionária deste se transformar em o presente em um lugar expandido e excêntrico de experiência e aquisição de poder. Por exemplo, se o interesse no pósmodernismo limitar-se a uma celebração da fragmentação das "grandes narrativas" do racionalismo pós-iluminista, então, apesar de toda a sua efervescência intelectual, ele permanecera um empreendimento profundamente provinciano (BHABBA, 1998, P. 23).

Ainda que recuse a perspectiva revolucionária, a sociedade hipermoderna se alimenta dela. A crítica deixa de ser intencionalmente revolucionária para ser midiática, é, pois, a “emoção ligada à novidade reconhecível, não forma da subversão" (Lipovetsky, 1989, p. 206) e, como atende as expectativas do mercado, os conflitos e disparidades sociais são aceitos, na medida em que serão logo substituído por outros. Como lembra Lipovetsky, "o individualismo atual não é o que abole as formas de participação nos combates coletivos, é o que transforma seu teor" $(1989$, p. 278).

Sem contradição, o anticonformismo e as revoluções foram aproveitadas para o mercado. Com o excesso de informações e discursos, suas possíveis disparidades com o próprio sistema não são mais que munições passageiras, cujos conflitos não assustam, pois não se sedimentam no pensamento do público. Assim é munido e alimentado um dos mais efêmeros mercados, a mídia, a qual, aliás, lucra com tal efemeridade.

Considerando-se as relações entre música e sociedade, o hábito de ouvir, as escolhas musicais e a própria orientação dos sucessos nas rádios seguem a tendência do que atende ao consumo e se as obras, como disse Adorno, representam tendências sociais, o mercado soube aproveitar-se disso, enxergando a todos como consumidores em potencial, apropriando-se dos estilos de cada grupo.

Onde começa, onde termina a moda, na era da explosão das necessidades e da mídia, da publicidade e dos lazeres de massa, das estrelas e dos sucessos musicais? O que não é, ao menos parcialmente, comandado pela moda quando o efêmero ganha o universo dos objetos, da cultura, dos discursos de sentido, quando o princípio de sedução reorganiza em profundidade o contexto cotidiano, a informação e a cena política? (LIPOVETSKY, 1989, p. 155)

Favorecida pelo advento de um mundo funcionalmente tecnológico e, orientada pela prática de mercado e pelo imediatismo do consumo, a indústria cultural atende 
quantitativamente à massa sem incorrer no erro da obsolescência. Assim, estimula necessidades artificiais e se organiza sob o princípio da novidade. Como diz Lipovetsky, "a novidade é a lei, com a condição de não ferir frontalmente o público, de não perturbar os hábitos e as expectativas, de ser imediatamente legível e compreensível para a maioria” (1989, p. 210).

\section{Conclusão}

Acerca do pensamento adorniano, pode-se compreender uma inegável ligação entre as tendências, e porque não dizer tensões, sociais com a música. Depreende-se das questões aqui discutidas e relacionadas à sociologia da música, de Adorno, bem como aos conceitos de hipermodernidade e cultura-mundo, de Gilles Lipovetsky, que a música utilitária atendeu às excentricidades do mercado e do consumo do entretenimento. No momento descrito por Adorno, entretanto, os discursos críticos faziam sentido. A mitificação do futuro por meio da crença no progresso e na tradição, o narcisismo coletivo ou, simplesmente, o orgulho nacional (Adorno, 2006) e o extremismo ideológico foram características da resistência desse tempo marcado pela força e pelo poder regulador e dicotômico dos grupos ou instituições sociais. A pós-modernidade, no entanto, representou o momento de emancipação e "a austeridade modernista declina em benefício da miscigenação sem fronteiras do antigo e do novo" (Lipovetsky, 1989, p. 273). A pós-modernidade não rejeita, apenas dessacraliza a fim de pulverizar valores, ressignificar possibilidades e legitimar escolhas.

Dizer que nossa sociedade funciona no presente não significa que o passado seja desvalorizado; significa que ele não é mais modelo a ser respeitado e reproduzido. Admiramo-lo, mas ele não comanda mais; as grandes obras do passado têm um imenso prestígio, mas produzimos 'sucessos' feitos para não durar, com obsolescência incorporada (LIPOVETSKY, 1989, p. 271).

Assim, apesar da promessa de bem-estar e prazer imediato, instalou-se, ao mesmo tempo, um tempo de desorientação generalizada, responsável pelo mais novo mal-estar na civilização. Se o passado deixa de ser uma referência, embora, como diz Lipovetsky, a valorização do passado seja um sintoma da pós-modernidade, a crítica feita em nome da tradição perde sua função em vista de uma esperança de libertação e autonomia aos padrões e uniformizações das ortodoxias doutrinárias. Mas, essa liberdade ocasionou sua própria desorientação e fragilidade, pois se tudo é permitido e legítimo, não se tem mais uma referência ou estrutura decodificadora do real que sirva como parâmetro ou como tradutora dos fatos. A ausência de um referencial incomoda a formação de uma autonomia subjetiva, o que faz com que o indivíduo busque por conta própria o consolo dos grupos. Nesse sentido, a formação do gosto e o juízo sobre a arte dependem de um aceite e compartilhamento. Os consagrados 
princípios da liberdade e autonomia individuais não são absorvidos na consciência coletiva nem mesmo foram suficientemente capazes de encorajar a emancipação. A conquista desses princípios assusta em face da necessidade de sua responsabilidade ética. Mas, "as referencias morais não desaparecem todas. Na verdade, as nossas sociedades organizam-se e pensam-se em torno dos valores humanistas essenciais, afirmados ainda com mais vigor por estar a declinar o empenho no domínio político" (Lipovetsky, 2010, p. 168).

Favorecendo a redução do tempo e, por conseguinte, o aumento da produção, o novo tempo consolidou a indústria cultural, organizada sob o princípio da novidade e da instabilidade do consumo. Assim, substituiu-se a tradição pelo ineditismo e pela originalidade que seduzem a massa proporcionando-lhe prazer imediato em vista de sua simplicidade que objetiva entreter, não educar ou insuflar valores superiores.

Contudo, à revelia das diferenças contextuais inerentes da diferença temporal que separa nossos autores, as conclusões de Adorno são recontextualizadas no tempo hipermoderno, descrito por Lipovetsky. Longe de não poder ser compreendida anos mais tarde, portanto, a crítica de Adorno vem, na verdade, confirmar-se na cultura-mundo, embora, para muitos, ela não passe de resquícios de um academicismo hermético, elitista e de valores ultrapassados não mais tolerados num presente tão efêmero, ordenado, como nas palavras de Lipovetsky, sob o código soberano da velocidade.

A crítica de Adorno não se torna obsoleta na cultura-mundo hipermoderna, pois esse novo momento soube se aproveitar do binarismo de suas diferenças. Valores tradicionais e necessidades mercantis, conservadores e liberais não protagonizam, desse modo, um conflito preocupante e a economia, inegavelmente, ainda se impõe sobre a produção cultural. Sem oposição com o presente, o passado é revitalizado e a mercantilização se amplia a todos os domínios.

Podemos, obviamente, dizer que "pela primeira vez aparece uma cultura produzida, não por uma elite social e intelectual, mas por toda a gente, sem fronteiras nacionais nem de classe" (Lipovetsky, 2010, P. 88); por outro lado, a cultura industrial transforma tudo o que convém em artigo de consumo que, sob a retórica da simplicidade, como diz Lipovetsky, não exige esforço por parte do público.

Trata-se de divertir, de dar prazer, de permitir uma evasão fácil e a cessível a todos, não requerendo nenhuma formação, nenhuma referencia cultural específica e erudita. O que a s indústrias culturais inventam não é senão uma cultura transformada em artigos de consumo de massas (LIPOVETSKY, 2010, P. 88).

\section{Referências:}


ADORNO, T. W. Introdução à Sociologia da Música: doze preleções teóricas. Trad. Por Fernando R. de Moraes Barros.- São Paulo: Editora Unesp, 2011.

- Por que é difícil a nova música? Trad. Flávio R. Kothe, in G. Cohn (org.), Col. Grandes Cientistas Sociais, vol. 54. São Paulo: Ática, 1986, p. 147-61. - Sobre música popular. Trad. Flávio R. Kothe, in G. Cohn, (org.), Col. Grandes Cientistas Sociais, vol. 54. São Paulo: Ática, 1986, p.115-146. - Educação e Emancipação. Trad. Wolfgang Leo Maar. Paz e Terra: São Paulo, 2006.

ADORNO, T. W., HORKHEIMER, M. Dialética do Esclarecimento: fragmentos filosóficos. Trad. Guido Antonio de Almeida. Rio de Janeiro: Jorge Zahar, 1985.

BHABHA, H. K. O local da cultura. Tradução de Myriam Ávila; Eliana Lourenço de Lima Reis e Gláucia Renate Gonçalves. Belo Horizonte: editora UFMG, 1998.

FREITAS, V. Para uma dialética da alteridade. A constituição mimética do sujeito, da razão e do tempo em Theodor Adorno. Belo horizonte: FAFICH/UFMG, 2001.

- Alteridade e transcendência: a dialética da arte moderna em Theodor Adorno. In: DUARTE, R.; FIGUEIREDO, V.; KANGUSSU, I. (Orgs.); Theoria Aesthetica. Em comemoração ao centenário de Theodor W. Adorno. Porto Alegre: Escritos, 2005.

LIPOVETSKY, G. A. O império do efêmero: a moda e seu destino nas sociedades modernas Tradução: Maria Lúcia Machado. São Paulo: Companhia das Letras, 1989. - A cultura-mundo: resposta a uma sociedade desorientada. Tradução: Victor Silva. Edições 70, 2010.

- Os tempos hipermodernos. Tradução: Mário Vilela. São Paulo: Editora Barcarolla, 2004.

Data de registro: 11/10/2018

Data de aceite: 30/08/2019 